\title{
Green Chemistry Solution to Environmental Problems
}

\author{
Ujang Supiandi ${ }^{1}$, Ferli S. Irwansyah ${ }^{2}$, Widodo Dwi Ismail Azis ${ }^{3}$, W Darmalaksana ${ }^{4}$ \\ \{ujangsupiandi93@gmail.com¹, ferli@uinsgd.ac.id², widododwiismailazis@uinsgd.ac.id², \\ yudi_darma@uinsgd.ac.id ${ }^{4}$ \} \\ UIN Sunan Gunung Djati Bandung, Indonesia ${ }^{1,2,3,4}$
}

\begin{abstract}
Conservation of nature and environment cannot be separated from the role of humans as a khalifah on earth, including the pollution and natural damage that occurred during this time. Lots of human activity, especially in the field of industries that produce emissions and pollute the environment which could interfere with human survival. Strategic solutions are needed to solve this problem generally, as well as comprehensive solutions to keep the environment clean and sustainable. The Green Chemistry concept, such as toxicology, hazard, and safety analysis, and energy efficiency, is one of the alternative solutions that can be implemented in education to produce an output with high environmental awareness. The application of Green Chemistry also conforms to the Islamic values that require humans to preserve nature and do no damage.
\end{abstract}

Keywords: Emission; Green Chemistry; Islamic values.

\section{Introduction}

The environment is the place where living things live. Throughout the history of humankind, environmental issues have taken a lot of attention in recent decades, due to the many disturbances of environmental ecosystem balance which are caused by human activities, especially in industry. The use of unwise chemicals in the synthesis process produces residues that pollute the environment. The effect is a crisis of natural resources, global warming, and climate change that are harmful to human survival.

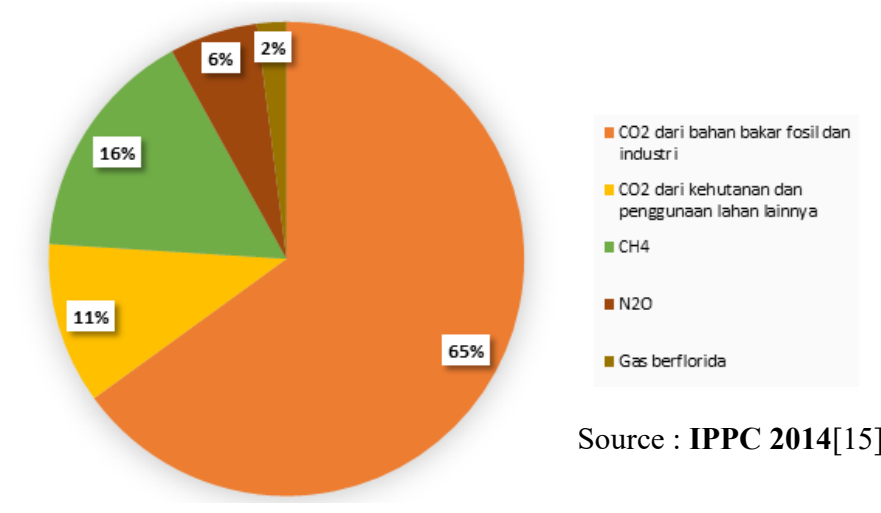

Figure. 1. Emissions of greenhouse gases from human activitutty, 2010 
The picture above shows the global emissions that occurred in 2010. Based on it, the most dominant greenhouse gas due to human activity is the CO2 gas. As much as $65 \%$ of CO2 gas is produced from fossil fuels and industrial processes while from forestry and other land use by $11 \%$. Other greenhouse gas emissions are $\mathrm{CH} 4$ gas at $16 \%$, $\mathrm{N} 2 \mathrm{O}$ at $6 \%$, and $2 \%$ fluoride gases.

The emergence of environmental problems must be repaired immediately. One improvement effort that can be done is by applying the concept of Green Chemistry in education. Through this concept, students who become agents of change are given an understanding of using the chemicals or synthesis methods that are environmentally friendly. So that is expected this concept becomes an educational paradigm and generates national awareness for caring the environment.

Green Chemistry in education is an alternative solution to the global challenges of sustainable development, which include population growth, energy production, energy use, food production, global climate change, environmental pollution, and a non-renewable natural resource crisis [1].

Application of green chemistry concepts in education conforms with the government educational programs for sustainable development. The principle of Green chemistry is to minimize harmful residues, optimize products, and utilize waste as a raw material product [2]. In addition, Green chemistry is a method to optimize current needs without compromising the ability for facing future needs.

Application of green chemistry in accordance with the Islamic Shari'a which advocates humanity as the Leader (Khalifah) on earth to protect and prohibit damaging the environment as His word in Q.S. Al A'raf verse 56, Q.S Al An'am verses 141-142. Allah SWT has bestowed the blessings of various natural resources that we should be grateful with utilizing and preserving them.

\section{Method}

\subsection{Data Collection Technique}

The technique used in data collection is literature study or library research, that is by collecting data in need both primary and secondary to discuss the theme thoroughly from several selected literature that has coherence with the research

\subsection{Data Analysis Technique}

The technique used in data analysis is descriptive qualitative analysis conducted inductively by taking general conclusions based on the results of the analysis.

\section{Result and Discussion}

\subsection{Concept of Green Chemistry}

The Green Chemistry concept emerged in 1990 aimed at reducing pollution using environmentally friendly solvents or green solvents. In the late 1990s, the idea of Green Chemistry began to grow slowly in Europe and the United States. His first concern was chemical synthesis and chemical engineering [3]. 
Green Chemistry applies the concept of using environmentally friendly chemicals. The synthesis process of a green chemistry-based product uses a method that can minimize hazardous waste, reactant efficiency, optimize the product, and by sustainable development [4]. Green chemistry focuses on technologies that can reduce or eliminate the use of hazardous materials and replace non-renewable raw materials with renewable materials. Also, the concept of green chemistry is to remove the toxicity of a product from the molecular level so that it is safe for humans and the environment [1].

Green Chemistry is an innovative approach that supports sustainable development. Green Chemistry prioritizes design process innovations that optimize performance and improve production by utilizing materials and energy that are safe for human health and the environment $[5]$.

\subsection{Principles of Green Chemistry}

Green chemistry has 12 basic principles in its applications. These principles were introduced by Paul Anastas and John Warner in 1998 [6]. These principles include, first, preventing waste better than tackling [7]. Second, design the experiments so that the material used in the reaction process becomes the product optimally. Thirdly, in practice, the synthesis methodology should use and produce substances that are a few toxic or even non-toxic. Fourth, in addition to reducing toxicity, chemical products should also be designed to achieve expected function effectiveness. Fifth, minimize the use of additional materials, if using it should not be dangerous. Sixth, minimize energy use. Seventh, renewable raw materials. Eighth, reduce the process of derivation. Ninth, the catalyst used should be effective, efficient, easy to use, and in accordance with the stoichiometric portion. Tenth, synthesized products are attempted to be biodegradable decomposed so they do not become pollutants in the environmental cycle process. Eleventh, Direct analysis to reduce contamination. The twelve, reagents or co-reagents used in chemical processes are pursued harmless to minimize accidents such as explosions and fires [8].

\subsection{Implementation of Green Chemistry in Education}

Green chemistry must be understood by every individual well to be able in life. One of the solutive steps to socialize Green Chemistry by putting it into education [9]. Education can contribute to the realization of Green Chemistry by providing students with knowledge of chemical products and sites with new, more environmentally friendly methods. Also, education plays a role in educating students in designing technology based on Green Chemistry as well as providing insight into how to operate it [10].

The implementation of green chemistry in education should be explored to be sustainable [2]. Implementation of Green Chemistry in education could be realized optimally with supported by two parties; they are government and educational institutions. 


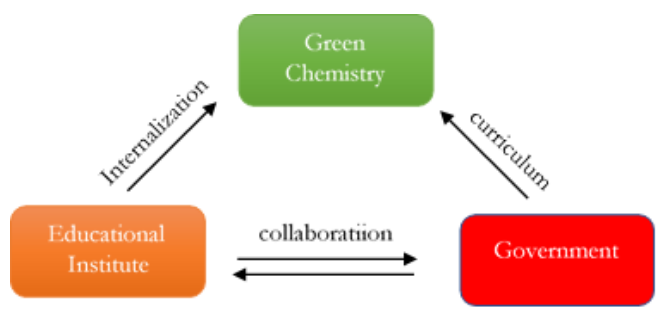

Figure. 2. The role of government and educational institutions in the implementation of Green Chemistry in education

The government is the policyholder that regulates the education component nationally, while the educational institutions are practitioners who implement policies that have been made by the government. Thus, both parties must synergize and harmonize because of mutual interconnection.

\subsection{Government Roles}

At least, there are two things the government can do to implement green chemistry in education, including:

\section{Incorporating Green Chemistry into the curriculum}

The implementation of Green Chemistry in education still has some problems such as the lack of a Green Chemistry concept in every sub-discipline of chemistry, the lack of a textbook that contains the concept of green chemistry, and the absence of primary sources that guide teachers. This happens because the concept of green chemistry is not yet listed in the curriculum [11].

The curriculum is a guideline for the implementation of national education. All aspects of learning are organized in the curriculum, including learning materials. Therefore, incorporating green chemistry into the curriculum and integrating it into the chemistry learning material is a solute step to educate the nation's generation on environmental issues. The application of Green Chemistry in the curriculum will help accelerate industrial pollution reduction because once students learn about the concept of pollution prevention, they will identify and develop techniques to reduce pollution in the industry [12]. In addition, the application of the Green Chemistry concept in education also contributes to sustainable development[13].

\section{Composing chemistry textbook based on Green Chemistry}

Besides containing Green Chemistry into the curriculum, it is also essential to compose textbooks based on Green Chemistry. It aims to facilitate educators and learners in searching for relevant learning references.

\section{Facilitating green chemistry training for educators}

Educators, as the spearhead of education, must have the skills to deliver materials or concepts of green chemistry in learning. Educators must be able to elaborate on the content until learners can understand and realize the importance of applying green chemistry in life. The skills must be trained, one of them by providing training for educators, as a workshop about green 
chemistry. Educators are supplied with materials and concrete examples related to green chemistry. It can help educators in implementation learning at the class based on green chemistry.

\subsection{Educational Institute Roles}

Specifically, the educational institute in this paper are educators, i.e. teachers or lecturers. Educator roles in the application of green chemistry are to provide information and internalization of the values which are contained in green chemistry towards students through the chemistry materials presented. In addition, educators also act as mentors in conducting experiments based on the principles of Green Chemistry. Several things can be done by educators to carry out its role, such as:

\section{Introducing the principles of green chemistry}

The first step is Students should understand the twelve principles of green chemistry to students. Students should follow it because it is necessary for applicating green chemistry. Furthermore, students can analyze how to apply green chemistry. This should be done intensely to form students paradigm in learning.

To facilitate in socializing the twelve principles of Green Chemistry, the educators convey the acronym, which is PRODUCTIVELY [14].

$\mathrm{P}=$ Prevent wastes

$\mathrm{R}=$ Renewable materials

$\mathrm{O}=$ Omit derivatization steps

$\mathrm{D}=$ Degradable chemical product

$\mathrm{U}=$ Use safe synthetic methods

$\mathrm{C}=$ Catalityc reagents

$\mathrm{T}=$ Temperature, pressure ambient

$\mathrm{I}=$ In Process monitoring

$\mathrm{V}=$ Very few auxiliary substances

$\mathrm{E}=\mathrm{E}$-factor, maximize feed in product

$\mathrm{L}=$ Low Toxicity of chemical product

$\mathrm{Y}=\mathrm{Yes}$, it is safe

\section{Creating an experiment module based on green chemistry concept}

The experiment is learning that must be existed in science, especially chemistry. Experiment serves to understand, proving, and applying the theory. However, in reality, there is a negative perception from students in chemistry learning, like the assumption that all chemical is frightening and dangerous. They associate chemicals with toxic; they judge that chemicals are not safety in an experiment [6]. It is indeed a proper thing because chemical experiment produces residues or emissions that are harmful to humans and the environment. Therefore, in applicating green chemistry, the guidance and modules of the experiment are needed. The developed module should be a methodology designed to reduce toxicity in every process of synthesis and to make the product optimally. 


\section{Conclusion}

Green Chemistry is one of the solutions to environmental problems that can be applied in the field of education. Green Chemistry in education is an effort to educate students in using chemicals wisely to do no damage to the environment. These efforts can be done by the roles of two parties, the government, and educational institute. Both must synergize to implement the Green Chemistry in education optimally and give positive impact to the environment

\section{Acknowledgments}

We thank to Puslitpen, LP2M UIN Sunan Gunung Djati Bandung who has funded so that this research can take place. 


\section{References}

[1] R. R. S. Saini and U. U. R. Singh, "Green chemistry: Environment, economics, and competitiveness," Corp. Environ. Strateg., vol. 9, no. 3, pp. 259-266, 2002.

[2] E. Kusrini, S. Harjanto, and A. H. Yuwono, "Applications of a green chemistry design, a clean environment, and bioenergy to promote the sustainability and added value of products," Int. J. Technol., vol. 6, no. 7, pp. 1065-1068, 2015.

[3] M. Wieczerzak, J. Namieśnik, and B. Kudłak, "Bioassays as one of the Green Chemistry tools for assessing environmental quality: A review," Environ. Int., vol. 94, pp. 341-361, 2016.

[4] M. Ulfah, P. Rahayu, and L. R. Dewi, "Konsep pengetahuan lingkungan green chemistry pada program studi pendidikan biologi." pp. 1-6, 2013.

[5] J. B. Manley, P. T. Anastas, and B. W. Cue, "Frontiers in Green Chemistry: meeting the grand challenges for sustainability in R\&D and manufacturing," J. Clean. Prod., vol. 16, no. 6, pp. 743-750, 2008.

[6] P. Anastas and N. Eghbali, "Green Chemistry: Principles and Practice," Chem. Soc. Rev., vol. 39, no. 1, pp. 301-312, 2010.

[7] P. T. Anastas and J. C. Warner, "Green Chemistry: Theory and Practice," Green Chem. Theory Pract., p. 135, 1998.

[8] S. Bradley, "Integrating safety into the undergraduate chemistry curriculum," J. Chem. Heal. Saf., vol. 18, no. 4, pp. 4-10, 2011.

[9] W. Wardencki, J. Curylo, and J. Namiesnik, "Green chemistry-current and future issues," Polish J. Environ. Stud., vol. 14, no. 4, pp. 389-395, 2005.

[10] M. M. Kirchhoff, "Promoting sustainability through green chemistry," Resour. Conserv. Recycl., vol. 44, no. 3 SPEC. ISS., pp. 237-243, 2005.

[11] J. Andraos and A. P. Dicks, "Research and Practice Green chemistry teaching in higher education : a review of effective practices w," pp. 69-79, 2012.

[12] D. L. Hjeresen, J. M. Boese, and D. L. Schutt, "Green Chemistry and Education," J. Chem. Educ., vol. 77, no. 12, p. 1543, 2000.

[13] J. L. Tucker, "Green chemistry: Cresting a summit toward sustainability," Org. Process Res. Dev., vol. 14, no. 2, pp. 328-331, 2010.

[14] S. L. Y. Tang, R. L. Smith, and M. Poliakoff, "Principles of green chemistry: PRODUCTIVELY," Green Chem., vol. 7, no. 11, p. 761, 2005.

[15] IPCC, Climate Change 2014: Mitigation of Climate Change. Summary for Policymakers and Technical Summary. 2014. 